\title{
Lumiracoxib is effective in the treatment of osteoarthritis of the knee: a 13 week, randomised, double blind study versus placebo and celecoxib
}

\author{
H Tannenbaum, F Berenbaum, J-Y Reginster, J Zacher, J Robinson, G Poor, H Bliddal, \\ D Uebelhart, S Adami, F Navarro, A Lee, A Moore, A Gimona
}

Ann Rheum Dis 2004;63:1419-1426. doi: 10.1136/ard.2003.015974

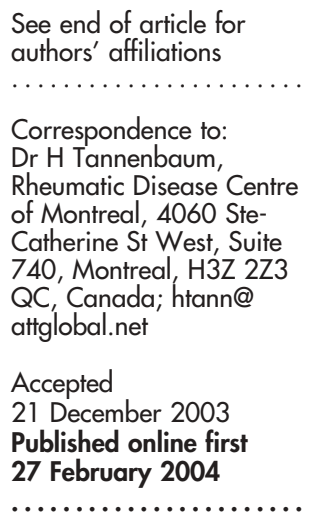

\begin{abstract}
Objectives: To compare the efficacy and safety of lumiracoxib with placebo and celecoxib for osteoarthritis $(\mathrm{OA})$ in a 13 week, multicentre, randomised, double blind study.

Methods: After a 3-7 day washout period for non-steroidal anti-inflammatory drugs, 1702 patients with knee OA were randomised to lumiracoxib 200 or $400 \mathrm{mg}$ once daily (od), celecoxib $200 \mathrm{mg}$ od, or placebo (2:2:2:1). A visual analogue scale (VAS) pain intensity $\geqslant 40 \mathrm{~mm}$ was required. Primary efficacy variables were OA pain intensity (VAS $\mathrm{mm}$ ) in the target knee, patient's global assessment of disease activity (VAS mm), and WOMAC pain subscale and total scores at 13 weeks. OA pain intensity, patient's and physician's global assessment of disease activity, and WOMAC (total and all subscale scores) were analysed by visit as secondary variables.

Results: Lumiracoxib showed significant improvements in all primary and secondary variables compared with placebo. Lumiracoxib $200 \mathrm{mg}$ od and celecoxib $200 \mathrm{mg}$ od achieved similar improvements in OA pain intensity and functional status. Lumiracoxib $400 \mathrm{mg}$ od demonstrated better efficacy for OA pain intensity and patient's global assessment of disease activity at weeks 2, 4, and 8 and similar efficacy at week 13 compared with celecoxib $200 \mathrm{mg}$ od. The incidence of adverse events (AEs), serious AEs, and discontinuations due to AEs was similar in each group.

Conclusion: Lumiracoxib demonstrated significant improvement in OA pain intensity, patient's global assessment of disease activity, and the WOMAC pain subscale and total scores compared with placebo. Lumiracoxib was well tolerated in this study, with overall tolerability similar to that of placebo and celecoxib.
\end{abstract}

O teoarthritis (OA) is a highly prevalent, chronic condition associated with a considerable burden for patients due to joint pain, stiffness, and inability to perform normal daily activities. As a result, this condition has a significant negative impact on quality of life. ${ }^{1}$

Non-steroidal anti-inflammatory drugs (NSAIDs) are well established as first line treatment for chronic moderatesevere pain in OA, providing effective relief of symptoms in most patients..$^{2-4}$ Traditional NSAIDs control the pain and inflammation associated with OA by reducing prostaglandin synthesis-a direct consequence of inhibitory effects on both isoforms of the cyclo-oxygenase (COX) enzymes (COX-1 and COX-2). This non-selective mechanism of action is largely responsible for the development of symptomatic ulcers and potentially serious gastrointestinal (GI) side effects. ${ }^{5}$ The incidence of symptomatic ulcers and ulcer complications associated with traditional NSAIDs was reported to be between 2 and $4 \%$ a year in $1988,{ }^{6}$ and the management of gastropathy associated with traditional NSAID use is estimated to more than double the costs associated with the original treatment. ${ }^{7}$ The concomitant use of gastroprotective agents with traditional NSAIDs has been reported as one possible approach to managing NSAID related gastropathy. ${ }^{8}$ The GI side effects are due to reduced synthesis of prostaglandins, which have a cytoprotective role in the GI tract, when COX-1 is inhibited by traditional NSAID treatment. ${ }^{9}$

Lumiracoxib is a new COX-2 selective inhibitor developed for the treatment of OA, rheumatoid arthritis (RA), and acute pain. It has demonstrated selectivity for COX-2 in vitro and in vivo $^{11}$ and in human studies, ${ }^{12}$ with selectivity maintained at doses up to $1200 \mathrm{mg}^{13}$ The structure of lumiracoxib distinguishes it from other COX-2 selective inhibitors, ${ }^{14}$ which may explain its preferential distribution into inflamed tissue in animal models (an effect not observed with other COX-2 selective inhibitors), ${ }^{15}$ and the sustained high concentrations of lumiracoxib seen in synovial fluid compared with plasma in patients with RA. ${ }^{17}$ Clinical studies show that lumiracoxib is characterised by rapid absorption ( $\mathrm{T}_{\max } 2-3$ hours), a short plasma half life (3-6 hours), ${ }^{18}$ and good oral bioavailability. ${ }^{19}$ In patients with OA, lumiracoxib demonstrates dose proportional pharmacokinetics. ${ }^{20}$ Once daily lumiracoxib provides relief from the pain, stiffness, and impaired physical function of OA with efficacy better than placebo and similar to diclofenac. ${ }^{21-23}$ Furthermore, lumiracoxib is associated with a GI tolerability profile better than ibuprofen and similar to celecoxib in patients with OA or RA. ${ }^{24} 25$

This study aimed at determining the efficacy of two doses of lumiracoxib (200 and $400 \mathrm{mg}$ once daily (od)) in relieving pain and improving functional status in patients with primary knee OA, compared with placebo and celecoxib $200 \mathrm{mg}$ od. The safety and tolerability profiles of all treatment groups were also assessed.

Abbreviations: $\mathrm{AE}$, adverse event; $\mathrm{COX}$, cyclo-oxygenase; DPDA difficulty in performing daily activities; ECG, electrocardiogram; GI, gastrointestinal; ITT, intention to treat; NOS, not otherwise specified; NSAID, non-steroidal anti-inflammatory drug; OA, osteoarthritis; od once daily; RA, rheumatoid arthritis; $\mathrm{SAE}$, serious adverse event; VAS, visual analogue scale; WOMAC, Western Ontario and McMaster Universities Osteoarthritis Index 
Table 1 Patient demographics and baseline disease characteristics

\begin{tabular}{|c|c|c|c|c|}
\hline & $\begin{array}{l}\text { Lumiracoxib } \\
200 \mathrm{mg} \text { od } \\
\text { ( } \mathrm{n}=487 \text { ) }\end{array}$ & $\begin{array}{l}\text { Lumiracoxib } \\
400 \mathrm{mg} \text { od } \\
\text { ( } \mathrm{n}=491)\end{array}$ & $\begin{array}{l}\text { Celecoxib } \\
200 \mathrm{mg} \text { od } \\
(\mathrm{n}=481)\end{array}$ & $\begin{array}{l}\text { Placebo } \\
(n=243)\end{array}$ \\
\hline Age (years), mean (SD) \{range\} & $64.1(10.7)\{20-93\}$ & $64.3(10.4\{20-92\}$ & $64.1(10.4\{30-91\}$ & $64.6\{9.9\{38-89\}$ \\
\hline \multicolumn{5}{|l|}{ Sex, No (\%) } \\
\hline Male & $148(30.4)$ & $160(32.6)$ & $148(30.8)$ & $80(32.9)$ \\
\hline Female & $339(69.6)$ & $331(67.4)$ & $333(69.2)$ & $163(67.1)$ \\
\hline White, No (\%) & $482(99.0)$ & $485(98.8)$ & $475(98.8)$ & $242(99.6)$ \\
\hline Body mass index $\left(\mathrm{kg} / \mathrm{m}^{2}\right)$, mean (SD) \{range & $29.5(5.8)\{17.1-62.1\}$ & $29.9(5.8)\{16.0-56.6\}$ & $30.0(5.7)\{18.4-63.6\}$ & $29.6(5.4)\{16.8-46.1\}$ \\
\hline OA disease duration (years), median & 4.2 & 5.2 & 5.3 & 4.3 \\
\hline OA pain intensity in target knee $(\mathrm{mm})$ & $65.5(14.9)$ & $65.1(14.1)$ & $65.1(14.2)$ & $65.7(13.3)$ \\
\hline Patient's global assessment of disease activity $(\mathrm{mm})$ & $62.9(17.4)$ & $62.6(17.6)$ & $63.6(18.0)$ & $63.2(16.5)$ \\
\hline Physician's global assessment of disease activity (mm) & $58.6(14.1)$ & $58.2(14.2)$ & $59.2(15.0)$ & $59.8(14.3)$ \\
\hline WOMAC total score & $49.0(14.9)$ & $48.1(15.0)$ & $48.7(15.4)$ & $49.2(14.0)$ \\
\hline WOMAC pain subscale score & $10.1(3.4)$ & $10.0(3.3)$ & $10.1(3.3)$ & $10.3(3.0)$ \\
\hline WOMAC DPDA subscale score & $34.6(11.2)$ & $33.9(11.4)$ & $34.4(11.7)$ & $34.6(10.4)$ \\
\hline WOMAC stiffness subscale score & $4.3(1.7)$ & $4.2(1.7)$ & $4.2(1.7)$ & $4.3(1.7)$ \\
\hline
\end{tabular}

Results are given as mean (SD) unless stated otherwise.

DPDA, difficulty in performing daily activities; OA, osteoarthritis; od, once daily; SD, standard deviation; WOMAC, Western Ontario and McMaster Universities Osteoarthritis Index.

\section{PATIENTS AND METHODS}

This 13 week international, multicentre, randomised, double blind, double dummy, placebo controlled, active comparator study, was performed in accordance with Good Clinical Practice guidelines and the Declaration of Helsinki (and subsequent amendments).

\section{Patients and study design}

Men and women aged $\geqslant 18$ years with a confirmed diagnosis of primary OA of the knee, according to the American College of Rheumatology criteria, ${ }^{26}$ were recruited after giving written, informed consent. Patients at risk of pregnancy or those who had secondary OA, other connective tissue diseases, or significant medical problems, were excluded.

People meeting the initial inclusion criteria underwent a 3-7 day washout period, during which NSAID treatment was not permitted. At the end of the washout period, patients with pain intensity in the affected knee measuring $\geqslant 40 \mathrm{~mm}$ on a $100 \mathrm{~mm}$ visual analogue scale (VAS) (most pain) in the past 24 hours were deemed eligible for entry into the treatment phase of the study. To best reflect the "real life" clinical situation, no increase/worsening in OA symptoms (flare) was required for study entry.

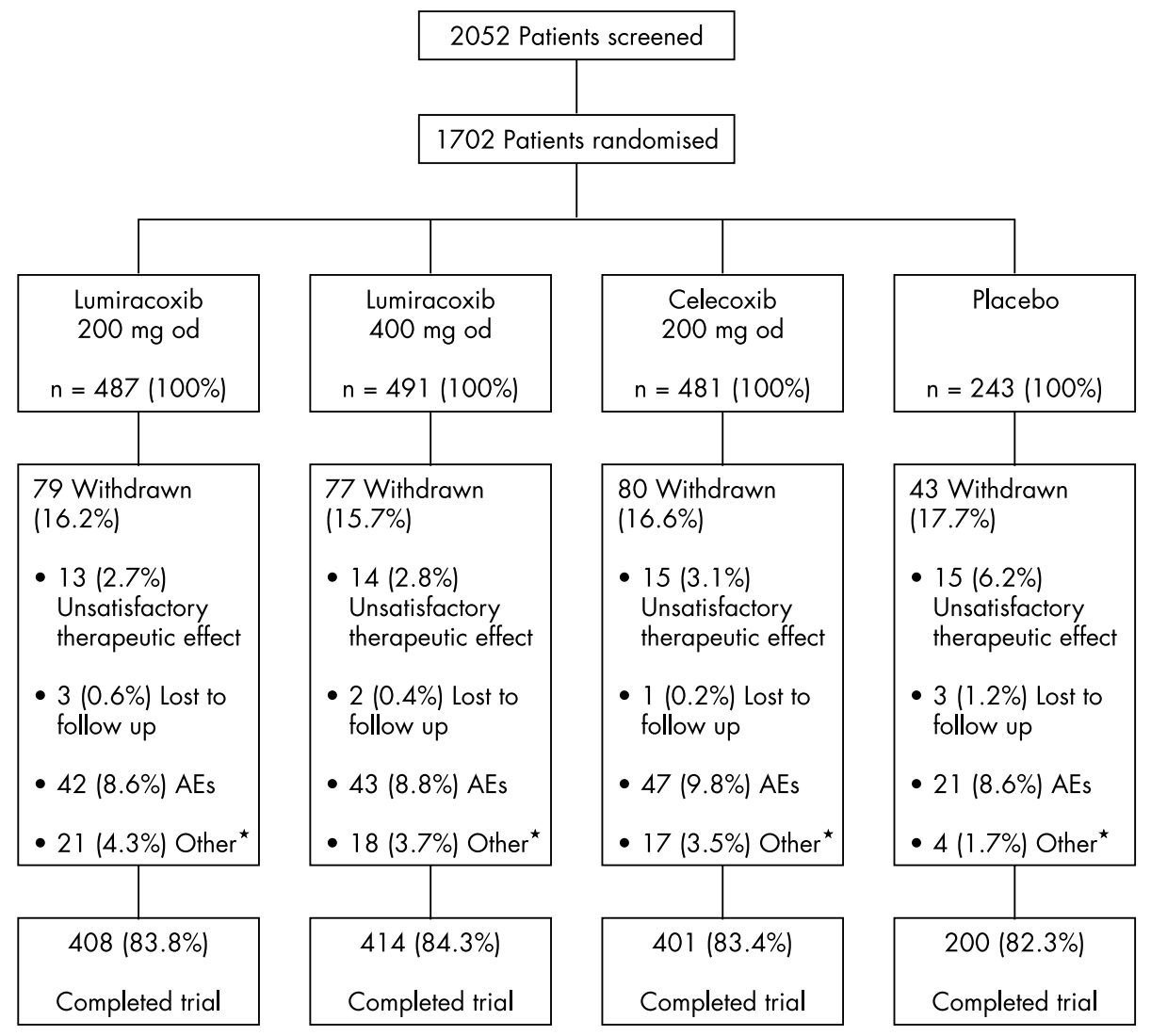

Figure 1 Patient flow diagram. *Other includes protocol violation, withdrawal of consent, and condition no longer requiring the study drug. 


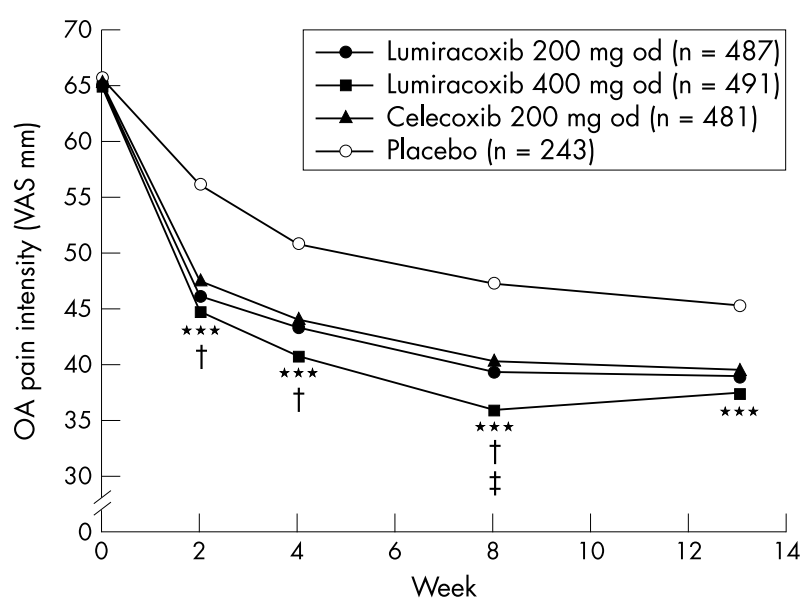

Figure 2 Osteoarthritis pain intensity (VAS $\mathrm{mm}$ ) in the target knee at weeks 2, 4, 8, and 13 with lumiracoxib (200 $\mathrm{mg}$ and $400 \mathrm{mg}$ od), celecoxib (200 mg od), and placebo. Values are least square means, except for baseline, which are means. ${ }^{* *} p \leqslant 0.001$ all active treatment groups $v$ placebo; $\uparrow \mathrm{p}<0.05$ lumiracoxib $400 \mathrm{mg}$ od $v$ celecoxib $200 \mathrm{mg}$ od; $\ddagger \mathrm{p}<0.05$ lumiracoxib $400 \mathrm{mg}$ od $v$ lumiracoxib $200 \mathrm{mg}$ od.

Patients were randomised to 13 weeks' once daily treatment with lumiracoxib $200 \mathrm{mg}$, lumiracoxib $400 \mathrm{mg}$, celecoxib $200 \mathrm{mg}$, or placebo. Celecoxib was administered at $200 \mathrm{mg}$ od according to its label specifications. Blinding was maintained by a double dummy technique. All drugs were taken in the morning at least 1 hour before or after a meal, the first dose being taken at the clinic on day 0 (baseline). After this, patients returned to the clinic for assessment at weeks 2, 4, 8, and 13.

Patients were permitted to take paracetamol ( $\leqslant 2$ g/day), supplied by the investigator, as a rescue drug throughout the trial; however, they were asked to refrain from using the rescue drug from midnight before each clinic visit. NSAIDs were not permitted during the course of the study, with the exception of low dose aspirin $(\leqslant 325 \mathrm{mg} /$ day) for a cardiovascular indication.

Prespecified criteria for discontinuation due to notable changes in laboratory measures were established.

\section{Outcome measures}

The following primary efficacy variables were evaluated at the end of the study (week 13):

- OA pain intensity (VAS mm) in the target knee (most pain in the previous 24 hours)

- Patient's global assessment of disease activity (VAS mm)

- Patient's functional status (pain subscale and total score of the Western Ontario and McMaster Universities Osteoarthritis Index (WOMAC) LK3.1 questionnaire). ${ }^{27}$
OA pain intensity in the target knee, patient's and physician's global assessment of disease activity, and WOMAC (total and all three subscale scores: pain, difficulty in performing daily activities (DPDA), and stiffness) were analysed by visit as secondary variables.

Safety was assessed through recording the frequency of adverse events (AEs) and serious adverse events (SAEs) at each clinic visit. Physical examinations were performed at baseline and at the study end, vital signs were assessed at each clinic visit, and standard laboratory tests were performed at weeks 2, 4, and 13. Electrocardiogram (ECG) measurements, analysed centrally, were conducted at screening, week 4, and week 13. A subgroup of patients, whose ECGs after baseline were recorded 1-4 hours after the morning dose of study drug to coincide with the maximum plasma concentration $\left(\mathrm{C}_{\max }\right)$ of lumiracoxib, ${ }^{18}$ were included into "peak time" analyses of ECG parameters.

Compliance with study treatment was monitored by pill counting, and rescue drug use was assessed at each study visit.

\section{Statistical analyses}

A minimum sample size of 432 patients in each active treatment group and 216 in the placebo group was specified in the study protocol-that is, a total of 1512 patients. Using a two group $t$ test with a 0.025 one tailed significance level, this sample size would have $99 \%$ power to reject the null hypothesis of no treatment difference over placebo, assuming a difference of $11 \mathrm{~mm}$ in favour of lumiracoxib, a withdrawal rate of $15 \%$, and a common standard deviation of $25 \mathrm{~mm}$. A high power was set to enable tests of non-inferiority or superiority of lumiracoxib to celecoxib. To this end,

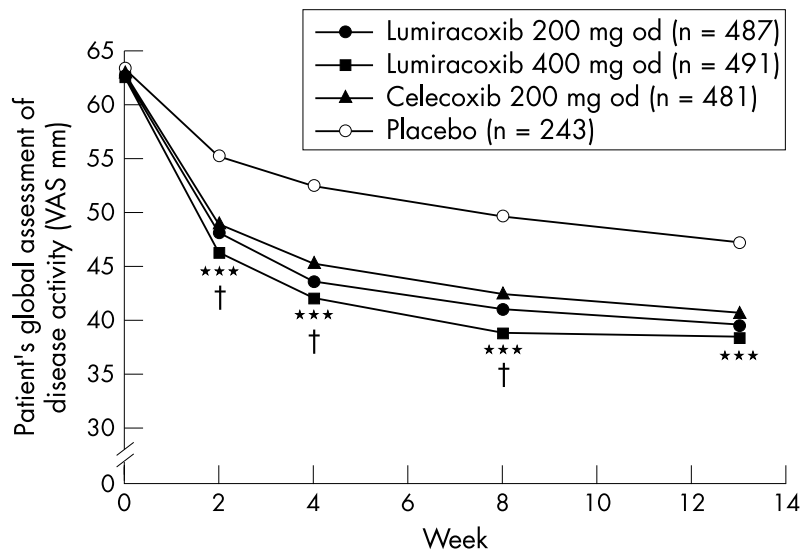

Figure 3 Patient's global assessment of disease activity (VAS $\mathrm{mm}$ ) at weeks 2, 4, 8, and 13 with lumiracoxib (200 $\mathrm{mg}$ and $400 \mathrm{mg}$ od), celecoxib (200 mg od), and placebo. Values are least square means, except for baseline, which are means. ${ }^{* * *} \mathrm{p} \leqslant 0.001$ all active treatment groups $v$ placebo; $\uparrow p<0.05$ lumiracoxib $400 \mathrm{mg}$ od $v$ celecoxib $200 \mathrm{mg}$ od.

Table 2 Change from baseline in OA pain intensity in the target joint, and patient's and physician's global assessments of disease activity at weeks 2 and 13

\begin{tabular}{|c|c|c|c|c|c|c|}
\hline & \multicolumn{2}{|c|}{ OA pain intensity in the target joint } & \multicolumn{2}{|c|}{$\begin{array}{l}\text { Patient's global assessment of } \\
\text { disease activity }\end{array}$} & \multicolumn{2}{|c|}{$\begin{array}{l}\text { Physician's global assessment of } \\
\text { disease activity }\end{array}$} \\
\hline & Week 2 & Week 13 & Week 2 & Week 13 & Week 2 & Week 13 \\
\hline $\begin{array}{l}\text { Lumiracoxib } 200 \mathrm{mg} \text { od }(n=487) \\
\text { Lumiracoxib } 400 \mathrm{mg} \text { od }(n=491) \\
\text { Celecoxib } 200 \mathrm{mg} \text { od }(n=481) \\
\text { Placebo }(n=243)\end{array}$ & $\begin{array}{l}-19.2(21.7) \\
-20.2(21.0) \\
-17.5(20.5) \\
-9.1(19.3)\end{array}$ & $\begin{array}{l}-26.0(26.3) \\
-27.4(24.5) \\
-25.2(24.7) \\
-19.8(26.1)\end{array}$ & $\begin{array}{l}-14.9(22.4) \\
-16.4(20.8) \\
-14.3(20.6) \\
-7.9(19.2)\end{array}$ & $\begin{array}{l}-23.2(26.9) \\
-24.1(25.0) \\
-22.4(25.7) \\
-15.7(26.1)\end{array}$ & $\begin{array}{l}-14.6(18.4) \\
-14.3(17.0) \\
-14.0(16.9) \\
-8.3(17.3)\end{array}$ & $\begin{array}{l}-23.0(22.4) \\
-23.6(21.4) \\
-22.4(22.0) \\
-18.0(24.3)\end{array}$ \\
\hline
\end{tabular}


non-inferiority margins of $5 \mathrm{~mm}$ for OA pain and patient's global assessment, and of 0.6 points for the pain subscale of the WOMAC questionnaire were predefined.

Patients were randomised in a ratio of 2:2:2:1 to 13 weeks' once daily treatment with lumiracoxib $200 \mathrm{mg}$, lumiracoxib $400 \mathrm{mg}$, celecoxib $200 \mathrm{mg}$, or placebo.

Each primary efficacy variable was analysed, using analysis of covariance, with baseline values as the covariate, with treatment group and study centre as the independent variables. Pairwise comparisons between treatments were performed using least square means obtained from the model. Data were analysed by visit at a secondary level using the same model.

All safety and efficacy evaluations were performed using the intention to treat (ITT) population. The safety and ITT populations were identical and included all patients randomised to treatment who had been exposed to the study drug. Conventional last observation carried forward methodology was used when data were missing.

In addition to the analysis of $\mathrm{AE}$ and SAE incidence, the incidence of prespecified AEs was compared in treated and placebo groups using medical terms as coded by a standard medical dictionary.

- Prespecified GI AEs and ulcers: abdominal pain not otherwise specified (NOS), abdominal pain lower, abdominal pain upper, abdominal pain aggravated, constipation, constipation aggravated, diarrhoea NOS, diarrhoea aggravated, nausea, nausea aggravated, vomiting NOS, vomiting aggravated, dyspepsia, dyspepsia aggravated, dysphagia, dysphagia aggravated, loose stools, oesophageal ulcer, peptic ulcer, peptic ulcer aggravated, gastric ulcer, duodenal ulcer, duodenal ulcer aggravated, gastroduodenal ulcer, GI ulcer, pyloric ulcer

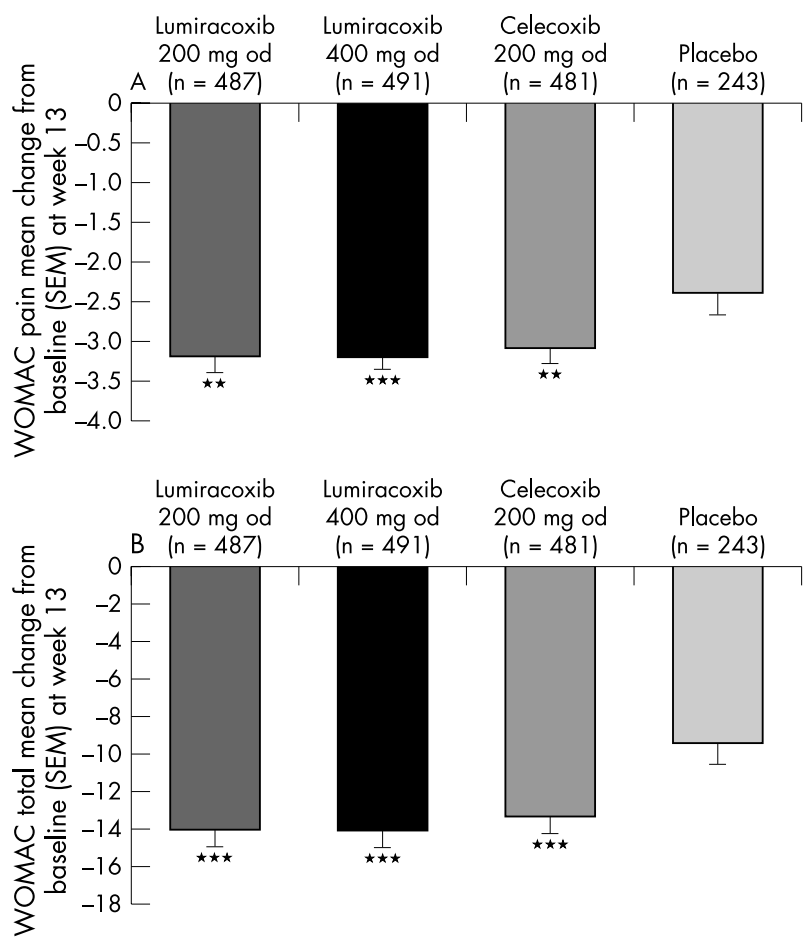

Figure 4 Mean (SEM) change from baseline in WOMAC pain subscale (A) and total (B) scores at week 13 with lumiracoxib $(200 \mathrm{mg}$ and $400 \mathrm{mg}$ od), celecoxib (200 mg od), and placebo. Statistical analyses performed using least square means. ${ }^{* *} p<0.01$ v placebo; ${ }^{* * *} p<0.001$ $\checkmark$ placebo.
- Peripheral oedema AEs: oedema peripheral, oedema lower limb, oedema NOS, oedema upper limb

- Chest pain AEs: chest pain not elsewhere classified.

Occurrence of prespecified AEs was summarised and analysed using a logistic regression model, including country and treatment group as variables.

\section{RESULTS}

\section{Patient characteristics}

The ITT population comprised 1702 patients, randomised to receive lumiracoxib $200 \mathrm{mg}$ od $(\mathrm{n}=487)$, lumiracoxib $400 \mathrm{mg}$ od $(\mathrm{n}=491)$, celecoxib $200 \mathrm{mg}$ od $(\mathrm{n}=481)$ or placebo $(n=243)$. The study group was predominantly female $(68.5 \%)$ with a mean age of approximately 64 years. There were no significant differences in patient demographics or baseline disease characteristics between the treatment groups (table 1).

A similar number of patients discontinued the study prematurely in each active treatment group (fig 1). Most discontinuations resulted from AEs; however, the proportion of patients who withdrew for this reason was similar across the four treatment groups. Overall, compliance with the treatment regimens was good, with more than $90 \%$ of patients judged to be compliant across the four treatment groups. Proportionately twice as many patients discontinued owing to a lack of efficacy in the placebo group as in the active treatment groups (fig 1).

\section{Efficacy}

\section{Primary variables}

All active treatments were statistically significantly better than placebo for each of the primary variables at 13 weeks.

For OA pain intensity (VAS mm) in the target knee at week 13 , the estimated least square mean differences from placebo in favour of active treatment were $6.33 \mathrm{~mm}(\mathrm{p}<0.001)$ in the lumiracoxib $200 \mathrm{mg}$ od group, $7.94 \mathrm{~mm}(\mathrm{p}<0.001)$ in the lumiracoxib $400 \mathrm{mg}$ od group, and $5.75 \mathrm{~mm}(\mathrm{p}=0.001)$ in the celecoxib $200 \mathrm{mg}$ od group (fig 2). The mean change from baseline in OA pain intensity at week 13 was similar for all active treatments $(-26.0 \mathrm{~mm}$ for lumiracoxib $200 \mathrm{mg}$ od, $-27.4 \mathrm{~mm}$ for lumiracoxib $400 \mathrm{mg}$ od, and $-25.2 \mathrm{~mm}$ for celecoxib $200 \mathrm{mg}$ od) compared with $-19.8 \mathrm{~mm}$ for placebo (table 2), and the non-inferiority of lumiracoxib 200 and $400 \mathrm{mg}$ od to celecoxib $200 \mathrm{mg}$ od was demonstrated.

Significant improvement in patient's global assessment of disease activity was seen in all active treatment groups at week 13 compared with placebo (all $\mathrm{p}<0.001 v$ placebo; fig 3 , table 2). All active treatments were similar and noninferiority of lumiracoxib 200 and $400 \mathrm{mg}$ od to celecoxib $200 \mathrm{mg}$ od was demonstrated.

The WOMAC pain subscale and total scores at week 13 were significantly better with lumiracoxib and celecoxib than with placebo (all $\mathrm{p}<0.01 v$ placebo for the pain subscale and all $\mathrm{p}<0.001$ for the total score). Figure 4 and table 3 show the mean changes from baseline.

\section{Secondary variables}

Significant improvements were seen in OA pain intensity (VAS $\mathrm{mm}$ ) in the target knee from week 2 onwards in all active treatment groups compared with placebo (table 2, fig 2). The reduction in pain intensity with lumiracoxib $200 \mathrm{mg}$ od was of similar magnitude to that of celecoxib $200 \mathrm{mg}$ od at all times. At weeks 2, 4, and 8, lumiracoxib $400 \mathrm{mg}$ od provided significantly greater reductions in OA pain intensity in the target knee than celecoxib $200 \mathrm{mg}$ od.

The patient's global assessment of disease activity (VAS $\mathrm{mm}$ ) was significantly improved from week 2 onwards in all active treatment groups compared with placebo (table 2, 
Table 3 Change from baseline in WOMAC total and subscale scores at weeks 2 and 13

\begin{tabular}{|c|c|c|c|c|c|c|c|c|}
\hline & \multicolumn{2}{|c|}{ WOMAC total score } & \multicolumn{2}{|c|}{ WOMAC pain subscale score } & \multicolumn{2}{|c|}{$\begin{array}{l}\text { WOMAC DPDA subscale } \\
\text { score }\end{array}$} & \multicolumn{2}{|c|}{$\begin{array}{l}\text { WOMAC stiffness subscale } \\
\text { score }\end{array}$} \\
\hline & Week 2 & Week 13 & Week 2 & Week 13 & Week 2 & Week 13 & Week 2 & Week 13 \\
\hline $\begin{array}{l}\text { Lumiracoxib } 200 \mathrm{mg} \text { od }(n=487) \\
\text { Lumiracoxib } 400 \mathrm{mg} \text { od }(n=491) \\
\text { Celecoxib } 200 \mathrm{mg} \text { od }(n=481) \\
\text { Placebo }(n=243)\end{array}$ & $\begin{array}{l}-10.6(13.2) \\
-9.8(13.9) \\
-8.6(13.1) \\
-4.3(12.4)\end{array}$ & $\begin{array}{l}-14.1(16.8) \\
-14.1(16.9) \\
-13.4(15.8) \\
-9.4(16.1)\end{array}$ & $\begin{array}{l}-2.6(3.3) \\
-2.6(3.4) \\
-2.4(3.1) \\
-1.4(3.3)\end{array}$ & $\begin{array}{l}-3.2(4.3) \\
-3.2(3.8) \\
-3.1(3.8) \\
-2.4(3.8)\end{array}$ & $\begin{array}{l}-6.9(9.6) \\
-6.4(10.3) \\
-5.5(9.9) \\
-2.4(8.8)\end{array}$ & $\begin{array}{l}-9.8(12.1) \\
-9.7(12.6) \\
-9.2(11.6) \\
-6.2(11.8)\end{array}$ & $\begin{array}{l}-1.0(1.7) \\
-0.9(1.6) \\
-0.8(1.6) \\
-0.5(1.5)\end{array}$ & $\begin{array}{l}-1.2(1.8) \\
-1.2(1.8) \\
-1.2(1.7) \\
-0.9(1.6)\end{array}$ \\
\hline
\end{tabular}

fig 3). In the lumiracoxib $400 \mathrm{mg}$ od group, the reduction in the mean score was significantly greater than in the celecoxib $200 \mathrm{mg}$ od group at weeks 2, 4, and 8 (fig 3). In addition, all active treatment groups were significantly more efficacious than placebo at weeks $2,4,8$, and 13 according to the physician's global assessment of disease activity (table 2).

Significant improvements were seen in WOMAC total and all three subscale scores for all active treatment groups compared with placebo at week 2 (all $\mathrm{p}<0.01 \quad v$ placebo; table 3). At week 13, all active treatments were associated with significant improvements according to the DPDA and stiffness subscales (all $\mathrm{p}<0.01 v$ placebo; table 3 ).

The mean number of rescue drug tablets consumed was significantly greater in the placebo group (0.8 tablets/day) than in any active treatment group throughout the study $(0.5$ tablets/day for both lumiracoxib groups and 0.6 tablets/day for celecoxib $200 \mathrm{mg}$ od; all $\mathrm{p}<0.05 v$ placebo). Betweentreatment analyses showed that at week 4 , the number of rescue drug tablets taken was significantly higher in the celecoxib $200 \mathrm{mg}$ od group than in the lumiracoxib $400 \mathrm{mg}$ od group; no other between-treatment differences were seen (data not shown).

\section{Safety}

Lumiracoxib was well tolerated. There were no deaths during the study and the incidence of SAEs was similar in all active treatment groups and the placebo group $(2.5 \%$ of patients receiving lumiracoxib $200 \mathrm{mg}$ od, $2.9 \%$ receiving lumiracoxib $400 \mathrm{mg}$ od, $2.9 \%$ receiving celecoxib $200 \mathrm{mg}$ od, and 3.3\% receiving placebo; table 4). The proportion of patients reporting at least one $\mathrm{AE}$ was $57.5 \%$ and $58.7 \%$ in the lumiracoxib $200 \mathrm{mg}$ od and $400 \mathrm{mg}$ od groups, respectively, compared with $51.0 \%$ for the placebo group and $53.2 \%$ for the celecoxib $200 \mathrm{mg}$ od group. AEs led to discontinuation from the study in a similar proportion of patients in each treatment group. In all treatment groups the most common AEs leading to discontinuation were those affecting the GI system: $18(3.7 \%)$ patients in the lumiracoxib $200 \mathrm{mg}$ od group, $22(4.5 \%)$ patients in the lumiracoxib $400 \mathrm{mg}$ od group, $19(4.0 \%)$ patients in the celecoxib $200 \mathrm{mg}$ od group, and $6(2.5 \%)$ patients in the placebo group (table 4$)$. In a post hoc analysis, no statistically significant differences were detected in discontinuation rates for GI AEs between any active treatments compared with placebo.

The majority of AEs were mild or moderately severe. The incidence and nature of AEs were similar in both lumiracoxib groups and the celecoxib group; overall, nasopharyngitis, headache, and upper abdominal pain, were the most commonly reported AEs in all treatment groups (table 5).

Multiple regression analyses of the incidence of prespecified AEs showed no significant differences between lumiracoxib and celecoxib (table 5). The proportion of patients reporting prespecified GI events was similar in each active treatment group. The incidence of prespecified peripheral oedema and chest pain was low, and no clinically relevant pattern was seen between treatment groups.

Clinically relevant laboratory abnormalities were uncommon in all treatment groups; however, four patients were withdrawn from the study because of abnormal values. As required by study protocol, one patient in the lumiracoxib $400 \mathrm{mg}$ od group discontinued because of a raised creatinine level ( $>2 \times$ the upper limit of normal). In total, nine patients had increases in liver function parameters (alanine aminotransferase/aspartate aminotransferase) $>3 \times$ the upper limit of normal (two patients in the lumiracoxib $200 \mathrm{mg}$ od group; three patients in the lumiracoxib $400 \mathrm{mg}$ od group; four patients in the celecoxib $200 \mathrm{mg}$ od group). Of these nine patients, three were withdrawn from the study (one patient in each of the lumiracoxib $200 \mathrm{mg}$ od, lumiracoxib $400 \mathrm{mg}$ od, and celecoxib $200 \mathrm{mg}$ od groups). All cases of raised liver function parameters resolved either while receiving the study drug or after treatment had stopped and none were accompanied by clinical symptoms.

ECG analyses showed that lumiracoxib was not associated with QT interval prolongation or any form of arrhythmia. There was no evidence of drug or dose related changes in ECG recordings or increase in qualitative ECG abnormalities in any treatment group.

\section{DISCUSSION}

The results of this large, randomised, double blind, placebo controlled, active comparator study demonstrate the clinical efficacy and tolerability of lumiracoxib, a new COX-2 selective inhibitor, at doses of 200 or $400 \mathrm{mg}$ od, in patients with OA of the knee. After 13 weeks of treatment, patients

Table 4 Summary of adverse events, serious adverse events, and discontinuations due to adverse events

\begin{tabular}{lllll}
\hline & $\begin{array}{l}\text { Lumiracoxib } \\
\mathbf{2 0 0} \mathbf{~ m g} \text { od } \\
(\mathbf{n = 4 8 7 )}\end{array}$ & $\begin{array}{l}\text { Lumiracoxib } \\
\mathbf{4 0 0} \mathbf{~ m g} \text { od } \\
(\mathbf{n = 4 9 1 )}\end{array}$ & $\begin{array}{l}\text { Celecoxib } \\
\mathbf{2 0 0} \mathbf{~ m g} \text { od } \\
(\mathbf{n = 4 8 1 )}\end{array}$ & $\begin{array}{l}\text { Placebo } \\
\text { (n= 243) }\end{array}$ \\
\hline Patients with SAEs & $12(2.5)$ & $14(2.9)$ & $14(2.9)$ & $8(3.3)$ \\
Patients with AEs & $280(57.5)$ & $288(58.7)$ & $256(53.2)$ & $124(51.0)$ \\
Discontinuations due to AEs & $42(8.6)$ & $43(8.8)$ & $47(9.8)$ & $21(8.6)$ \\
Discontinuations due to Gl AEs & $18(3.7)$ & $22(4.5)$ & $19(4.0)$ & $6(2.5)$ \\
\hline Results are shown as No (\%). & & & & \\
AE, adverse event; Gl, gastrointestinal; od, once daily; SAE, serious adverse event. &
\end{tabular}


Table 5 Incidence of most frequently reported adverse events (>3\%) and prespecified adverse events

\begin{tabular}{|c|c|c|c|c|}
\hline & $\begin{array}{l}\text { Lumiracoxib } \\
200 \mathrm{mg} \text { od } \\
\text { ( } \mathrm{n}=487)\end{array}$ & $\begin{array}{l}\text { Lumiracoxib } \\
400 \mathrm{mg} \text { od } \\
\text { ( } \mathrm{n}=491)\end{array}$ & $\begin{array}{l}\text { Celecoxib } \\
200 \mathrm{mg} \text { od } \\
\text { ( } \mathrm{n}=481)\end{array}$ & $\begin{array}{l}\text { Placebo } \\
(n=243)\end{array}$ \\
\hline \multicolumn{5}{|c|}{ Most frequently reported $A E s$} \\
\hline Nasopharyngitis & $34(7.0)$ & $28(5.7)$ & $23(4.8)$ & $12(4.9)$ \\
\hline Headache & $19(3.9)$ & $29(5.9)$ & $27(5.6)$ & $9(3.7)$ \\
\hline Abdominal pain upper & $23(4.7)$ & $25(5.1)$ & $25(5.2)$ & $6(2.5)$ \\
\hline Arthralgia & $15(3.1)$ & $11(2.2)$ & $14(2.9)$ & $11(4.5)$ \\
\hline Dyspepsia & $19(3.9)$ & $21(4.3)$ & $17(3.5)$ & $9(3.7)$ \\
\hline Diarrhoea & $13(2.7)$ & $18(3.7)$ & $11(2.3)$ & $2(0.8)$ \\
\hline Back pain & $8(1.6)$ & $14(2.9)$ & $17(3.5)$ & $8(3.3)$ \\
\hline Hypertension NOS & $8(1.6)$ & $17(3.5)$ & $12(2.5)$ & $2(0.8)$ \\
\hline Influenza & $11(2.3)$ & $16(3.3)$ & $11(2.3)$ & $7(2.9)$ \\
\hline Prespecified AEs & 94 (19.3) & $101(20.6)$ & $77(16.0)$ & $30(12.3)$ \\
\hline $\mathrm{Gl}$ events & 85 (17.5) & $96(19.6)$ & $72(15.0)$ & $25(10.3)$ \\
\hline Peripheral oedema & $6(1.2)$ & $4(0.8)$ & $6(1.2)$ & $4(1.6)$ \\
\hline Chest pain & $3(0.6)$ & $4(0.8)$ & $2(0.4)$ & $1(0.4)$ \\
\hline
\end{tabular}

who had received lumiracoxib 200 and $400 \mathrm{mg}$ od had significantly less OA pain intensity in the target knee, and better patient's global assessment of disease activity and patient's functional status than the placebo group.

Analyses of $\mathrm{OA}$ pain intensity in the target knee and patient's global assessment of disease activity by clinic visit (secondary variables) showed that both doses of lumiracoxib provided statistically significant improvements over placebo from the first clinic visit after the start of treatment (week 2), an effect sustained throughout the study. The magnitude of improvement was similar for lumiracoxib $200 \mathrm{mg}$ od and celecoxib $200 \mathrm{mg}$ od at all times. Lumiracoxib $400 \mathrm{mg}$ od was significantly more effective than celecoxib $200 \mathrm{mg}$ od at weeks 2,4 , and 8 , but no significant differences were seen by the study end (week 13). For the other secondary efficacy variables, physician's global assessment of disease activity, and WOMAC DPDA and stiffness subscales, both lumiracoxib groups and the celecoxib group were significantly better than placebo throughout the study.

Celecoxib has been shown to provide sustained analgesic effects and improvements in physical function in patients with OA, with efficacy better than placebo and similar to that of the traditional NSAIDs, naproxen and diclofenac. ${ }^{28} 29$ Celecoxib was therefore chosen as a reference treatment for this study, and was used at the recommended dose for the treatment of $\mathrm{OA}^{30}$ Thus, it is notable that in this study lumiracoxib $200 \mathrm{mg}$ od was found to be similar to celecoxib in all clinical efficacy measures examined.

This study recruited patients without OA flare to replicate the "real life" clinical situation for patients with OA. In previously reported celecoxib studies in OA, a flare design was used, whereby patients were required to demonstrate a worsening in OA symptoms during an NSAID washout period between screening and baseline. ${ }^{28} 31$ In both these studies a marked placebo effect was seen in the mean change from baseline in OA pain intensity (VAS mm), and celecoxib was associated with mean changes from baseline of up to $-30.0 \mathrm{~mm}$ and differences in comparison with placebo of up to $-15.0 \mathrm{~mm}$ after 2 weeks of treatment. ${ }^{28}{ }^{31}$ In our study the lack of a requirement for OA flare would be expected to provide an overall less dramatic treatment effect and, consequently, a smaller difference compared with placebo.

In addition, it has recently been suggested that the concept of a minimal clinically perceptible difference is applicable to the WOMAC DPDA subscale, whereby the minimal difference perceived by $75 \%$ of patients (MDP75) is considered to represent a clinically meaningful difference. In a study sample of 1354 patients with hip and knee OA, the MDP75 for the WOMAC DPDA subscale was found to be 5.2. ${ }^{32}$ It is notable that in the study reported here, mean changes in WOMAC DPDA subscale scores were $>6$ for both doses of lumiracoxib at week 2 , rising to $>9$ at week 13 .

Celecoxib and rofecoxib are associated with a lower incidence of ulcers and GI events than traditional nonselective NSAIDs. ${ }^{33-35}$ Although the results of the Celecoxib Outcomes Study (CLASS) were not positive for celecoxib compared with traditional non-selective NSAIDs for ulcer related complications at 12 months, ${ }^{36}{ }^{37}$ a recent systematic review of a wide range of celecoxib studies found that it does offer significantly improved GI safety and tolerability (including ulcers and serious upper GI events) compared with traditional NSAIDs. ${ }^{38}$ In this study both doses of lumiracoxib and celecoxib were associated with a similar incidence of AEs, including GI disorders, suggesting no dose relationship. In addition, the number of patients who withdrew from the study because of AEs or GI-specific AEs was similar across all active treatment groups. Furthermore, lumiracoxib was not associated with an increase in overall renal AEs or associated symptoms of oedema compared with placebo, and did not result in QT interval prolongation or any form of arrhythmia.

The efficacy and tolerability of lumiracoxib seen in this study confirm findings of earlier studies in patients with OA. In a 4 week study of 583 patients with primary OA of the hip and knee, lumiracoxib demonstrated efficacy comparable with the traditional NSAID, diclofenac, for pain relief, improved functional status, and response to treatment. ${ }^{21}$ In a 13 week study comparing the GI effects of lumiracoxib with ibuprofen and celecoxib in 1042 patients with primary OA of the hip, knee, hand, or spine, lumiracoxib was associated with significantly fewer gastroduodenal ulcers than ibuprofen. In addition, it was notable that lumiracoxib and celecoxib demonstrated a similar GI tolerability profile. ${ }^{24}$ Lumiracoxib resulted in significantly lower rates of gastroduodenal ulceration than ibuprofen in a separate study of 893 patients with RA; the incidence of gastroduodenal ulcers was also similar for lumiracoxib and celecoxib in this study. ${ }^{25}$ Similarly, in healthy volunteers, lumiracoxib was associated with a reduced incidence of gastroduodenal erosions compared with the traditional NSAID, naproxen. ${ }^{12} 39$

In summary, our study shows that lumiracoxib at a dose of 200 or $400 \mathrm{mg}$ od provides sustained relief from the painful 
symptoms of OA of the knee and improves functional status with significantly better efficacy than placebo. In addition, lumiracoxib was found to be as effective and well tolerated as the recommended dose of the established COX-2 selective inhibitor, celecoxib.

\section{ACKNOWLEDGEMENTS}

We thank J-Y Robo (programmer), A Couturier (statistical programmer), and D Jack (senior clinical research scientist).

A Lee, A Moore, and A Gimona are employees of Novartis Pharma AG, Basel, Switzerland.

This study was supported by a grant from Novartis Pharma AG, Basel, Switzerland.

\section{INVESTIGATORS}

Belgium: Dr F Raeman, Merksem; Professor J-Y Reginster, Liege; Dr F Van Bruwaene, Roeselare; Dr P Van Wanghe, Hasselt; Dr L Williame, Antwerp; Dr M Wouters, Brussels.

Canada: Dr M Bell, Toronto; Dr W Bensen, Hamilton; Dr J Brown, Ste-Foy; Dr B Haraoui, Montreal; Dr S Huang, Vancouver; Dr M Luterman, Downsview; Dr J-P Ouellet, Sherbrooke; Dr H Tannenbaum, Montreal; Dr E Wasser, Toronto; Dr K White, London.

Denmark: Dr T Aaboe, Copenhagen; Dr J Beier, Odense; Dr H Bliddal, Frederiksberg; Dr HH Ibfelt, Hilleroed; Dr B Lund, Copenhagen; Dr O Nedergaard, Hvidovre.

France: Dr L Boucher, Murs Erigne; Dr S Boutboul, Marseille; Dr A Boye, Nantes; Dr C Copere, Roanne; Dr D Dubourg, Saint Viaud; Dr G Etchegaray, Niort; Dr P Lafont, Uzes; Dr G Mongin, Montpellier; Dr S Musso, Eaunes; Dr E De Sainte Lorette, Paris; Dr R Sarfati, La Seyne Sur Mer.

Germany: Dr R Alten, Berlin; Professor Dr B Fink, Hamburg; Professor J Grifka, Bad Abbach; Professor H Grobecker, Regensburg; Professor H Haentzschel, Leipzig; Professor F-W Hagena, Bad Oeynhausen; Professor G Hein, Jena; Professor H-R Henche, Rheinfelden; Professor E Hille, Hamburg; Dr E Schell, Nuernberg; Dr H Schneider, Messkirch; Professor J Sieper, Berlin; Dr M Talke, Berlin; Dr H Thabe, Bad Kreuznach; Professor G Weseloh, Erlangen; Professor H Wittenberg, Bochum; Dr A Wittenborg, Herne; Professor Dr J Zacher, Berlin.

Hungary: Dr G Genti, Kistarcsa; Dr G Poor, Budapest; Dr F Szanyo, Gyor; Dr L Tamasi, Miskolc.

Italy: Professor S Adami, Verona; Dr G Bianchi, Arenzano; Professor S Bombardieri, Pisa; Dr M Broggini, Varese; Professor M Carrabba, Milano; Dr M Fasani, Roma; Professor R Marcolongo, Siena; Dr M Muratore, San Cesario di Lecce; Dr C Salvarani, Reggio Emilia; Professor B Seriolo, Genova.

Spain: Dr A Alonso, Bilbao; Dr P Benito, Barcelona; Dr F Buitrago, Badajoz; Dr E Chamizo, Mérida Badajoz; Dr E Collantes, Córdoba; Dr M Figueroa, San Sebastián Guipúzcoa; Dr A Garcia, Seville; Dr C Gonzáez, Madrid; Dr F Navarro, Seville; Dr J Orte, Madrid; Dr V Rodríguez, Santander; Dr M Rodríguez, Málaga; Dr JA Roman, Valencia; Dr J Sampedro, Toledo; Dr J Tornero, Guadalajara. Switzerland: Dr A Aeschlimann, Zurzach; Dr G Ambrosini, Bellinzona; Dr H Gerber, Zürich; Dr P Hasler, Aarau; Dr PJ Jenoure, Muttenz; Dr N Masina, Lugano; Dr M Pellaton, Neuchâtel; Dr J Sturzenegger, Kreuzlingen; Dr R Theiler, Zürich; Dr D Uebelhart, Zürich; Dr J-J Volken, Sierre.

United Kingdom: Dr K Brown, Liverpool; Dr D Dev, Manchester; Dr G Ding, Didcot; Dr J Fraser, Wigan; Dr B Grimshaw, Reading; Dr C Harding, Cardiff; Dr J Robinson, Liverpool; Dr M Salman, Birmingham; Dr I Smith, Glasgow; Dr S Taylor, Chorley.

\section{Authors' affiliations}

H Tannenbaum, Rheumatic Disease Centre of Montreal, Montreal, Canada

F Berenbaum, Hôpital St Antoine, Paris, France

J-Y Reginster, CHU de Liège, Liège, Belgium

J Zacher, Orthopädische Klinik, HELIOS Klinikum Berlin, Germany

J Robinson, Synexus Ltd, Liverpool, UK

G Poor, Orszagos Reumatologiai es Fizioterapias, Budapest, Hungary

H Bliddal, Frederiksberg Hospital, Frederiksberg, Denmark

D Uebelhart, Universität Zurich, Zurich, Switzerland

S Adami, Centro di Osteoporosis, Verona, Italy

F Navarro, Hospital Universitario Virgen Macarena, Sevilla, Spain

A Lee, A Moore, A Gimona, Novartis Pharma AG, Basel, Switzerland

\section{REFERENCES}

1 Reginster JY. The prevalence and burden of arthritis. Rheumatology (Oxford) 2002;41(suppl 1):3-6.

2 ACR. Recommendations for the medical management of osteoarthritis of the hip and knee: 2000 update. American College of Rheumatology Subcommittee on Osteoarthritis Guidelines. Arthritis Rheum 2000;43:1905-15

3 Dougados $M$. The role of anti-inflammatory drugs in the treatment of osteoarthritis: a European viewpoint. Clin Exp Rheumatol 2001;19(suppl 25):S9-14.

4 Moskowitz RW. The role of anti-inflammatory drugs in the treatment of osteoarthritis: a United States viewpoint. Clin Exp Rheumatol 2001; 19(suppl 25):S3-8.

5 Hernandez-Diaz S, Garcia Rodriguez LA. Epidemiological assessment of the safety of conventional nonsteroidal anti-inflammatory drugs. Am J Med $2001 ; 110$ (suppl 3A):20-7S.

6 Paulus HE. FDA arthritis advisory committee meeting: serious gastrointestinal toxicity of nonsteroidal anti-inflammatory drugs; drug-containing renal and biliary stones; diclofenac and carprofen approved. Arthritis Rheum 1988;31:1450-1.

7 Moore RA. The hidden costs of arthritis treatment and the cost of a new therapy-the burden of non-steroidal anti-inflammatory drug gastropathy. Rheumatology (Oxford) 2002;41(suppl 1):7-15.

8 Rostom A, Dube C, Wells G, Tugwell P, Welch V, Jolicoeur E, et al. Prevention of NSAID-induced gastroduodenal ulcers. Cochrane Database Syst Rev 2000;4:CD002296.

9 Vane J, Botting R. Inflammation and the mechanism of action of antiinflammatory drugs. FASEB J 1987; 1:89-96.

10 Fitzgerald GA, Patrono $C$. The coxibs, selective inhibitors of cyclooxygenase2. N Engl J Med 2001;345:433-42.

11 Marshall PJ, Berry JC, Wasvary J, Van Duzer J, Scott G, Rordorf C, et al. The in vitro and in vivo selectivity of COX189, a new and highly selective inhibitor of COX-2. Ann Rheum Dis 2002;61 (suppl I):259 (abstr SAT0013).

12 Atherton CT, Jones JI, McKaig BC, Bebb J, Cunliffe R, Burdsall J, et al. Pharmacology and gastrointestinal safety of lumiracoxib, a novel cyclooxygenase-2 selective inhibitor: an integrated study. Clin Gastroenterol Hepatol 2004; 2:113-20.

13 Scott G, Rordorf C, Milosavljev S, Chase W, Fleischmann R, Kivitz A. Multipledose lumiracoxib shows rapid absorption and COX-2 selectivity without accumulation in patients with rheumatoid arthritis. In: Tulunay FC, Orme M, eds. European collaboration: towards drug development and rational drug therapy. Proceedings of the Sixth Congress of the European Association for Clinical Pharmacology and Therapeutics. Berlin: Springer, 2003:124 (abstr P-197)

14 Mangold JB, Gu H, Rodriguez LC, Bonner J, Dickson J, Rordorf C. Pharmacokinetics and metabolism of lumiracoxib in healthy male subjects. Drug Metab Dispos 2004;32:566-71

15 Weaver ML, Flood DJ, Kimble EF, Fujimoto RA. Lumiracoxib demonstrates preferential distribution to inflamed tissue in the rat following a single oral dose: an effect not seen with other cyclooxygenase-2 inhibitors. Ann Rheum Dis 2003;62(suppl I):378 (abstr AB0044).

16 Dawson J, Jagher B, Toscano KT, Fujimoto RA, Quadros E. Lumiracoxib shows rapid distribution to inflamed sites in a rat tissue chamber model compared with rofecoxib and celecoxib. Ann Rheum Dis 2003;62(suppl I): 377 (abstr AB0042).

17 Scott G, Rordorf C, Reynolds C, Kalbag J, Looby M, Milosavliev S, et al. Pharmacokinetics of lumiracoxib in plasma and synovial fluid. Clin Pharmacokinet 2004;43:467-78.

18 Scott G, Rordorf C, Blood P, Branson J, Milosavliev S, Greig G. Dose escalation study to assess the safety, tolerability, pharmacokinetics and pharmacodynamics of COX189 in healthy subjects. Ann Rheum Dis 2002;61:242(suppl I):242 (abstr FRI0300).

19 Hartmann S, Scott G, Rordorf C, Campestrini J, Branson J, Keller U. Lumiracoxib demonstrates high absolute bioavailability in healthy subjects. In: Tulunay FC, Orme M, eds. European collaboration: towards drug development and rational drug therapy. Proceedings of the Sixth Congress of the European Association for Clinical Pharmacology and Therapeutics. Berlin: Springer, 2003:124 (abstr P-199).

20 Scott G, Branson J, Milosavljev S, Rordorf C, Haraoui B, Ouellet J-P, et al. Lumiracoxib demonstrates dose-proportional and time-independent pharmacokinetics in patients with osteoarthritis of the knee. Ann Rheum Dis 2003;62(suppl I):267 (abstr FRI0235).

21 Schnitzer TJ, Geusens P, Hasler P, Patel SK, Poor G, Senffleber I, et al. Efficacy and safety of COX189 in osteoarthritis: a multi-national study. Arthritis Rheum 2000;43(suppl 9):1616 (abstr S336).

22 Benevolenskaya L, Tüzün S, Hagin E, Moore A, Gimona A. Lumiracoxib is effective in relieving symptoms of knee or hip osteoarthritis after 4 weeks of treatment: results from a randomized, placebo-controlled trial. Ann Rheum Dis 2003;62(suppl I):270 (abstr FRI0246)

23 Grifka J, Zacher J, Brown J, Seriolo B, Lee A, Moore A, et al. Lumiracoxib is effective and well tolerated in patients with osteoarthritis of the hand: results from a randomized, placebo-controlled trial. Ann Rheum Dis 2003;62(suppl I):263 (abstr FRIO222).

24 Hawkey CJ, and the PUCCINI (Prevention of Ulcers with COX189 Compared with Ibuprofen In NSAID Investigation) study group. Reduced cumulative incidence of gastroduodenal ulcers with two doses of a new coxib, COX189 compared with standard therapeutic doses of ibuprofen in osteoarthritis patients. Gastroenterology 2002;122(suppl 1):A-345 (abstr M1732).

25 Kivitz AJ, Nayiager S, Schimansky T, Gimona A, Thurston HJ, Hawkey CJ. Reduced incidence of gastroduodenal ulcers associated with lumiracoxib 
compared with ibuprofen in patients with rheumatoid arthritis. Aliment Pharmacol Ther 2004;19:1189-98.

26 Altman R, Asch E, Bloch D, Bole G, Borenstein D, Brandt K, et al. Development of criteria for the classification and reporting of osteoarthritis. Classification of osteoarthritis of the knee. Arthritis Rheum 1986;29:1039-49.

27 Bellamy N, Buchanan WW, Goldsmith, CH, Campbell J, Stitt LW. Validation study of WOMAC: a health status instrument for measuring clinically important patient relevant outcomes to antirheumatic drug therapy in patients with osteoarthritis of the hip or knee. J Rheumatol 1988;15:1833-40.

28 Bensen WG, Fiechtner JJ, McMillen Jl, Zhao WW, Yu SS, Woods EM, et al. Treatment of osteoarthritis with celecoxib, a cyclooxygenase-2 inhibitor: a randomized controlled trial. Mayo Clin Proc 1999;74:1095-105.

29 McKenna F, Borenstein D, Wendt H, Wallemark C, Lefkowith JB, Geis GS. Celecoxib versus diclofenac in the management of osteoarthritis of the knee. A placebo-controlled, randomised, double-blind comparison. Scand J Rheumatol 2001;30:11-18.

30 Celecoxib (Celebrex ${ }^{\circledR}$ ) Package Insert. Pharmacia Pfizer, 2000.

31 Simon LS, Lanza FL, Lipsky PE, Hubbard RC, Talwalker S, Schwartz BD, et al. Preliminary study of the safety and efficacy of SC-58635, a novel cyclooxygenase 2 inhibitor: efficacy and safety in two placebo-controlled trials in osteoarthritis and rheumatoid arthritis, and studies of gastrointestinal and platelet effects. Arthritis Rheum 1998;41:1591-602.

32 Falissard B, Ravaud P, Tubach F, Logeart I, Baron G, Dougados M. Determination of a minimal clinically meaningful difference in the WOMAC physical function score: application of a new concept, the MDP75. Ann Rheum Dis 2003;62(suppl I):267 (abstr FRI0236).
33 Goldstein JL, Silverstein FE, Agrawal NM, Hubbard RC, Kaiser J, Maurath CJ, et al. Reduced risk of upper gastrointestinal ulcer complications with celecoxib, a novel COX-2 inhibitor. Am J Gastroenterol 2000;95:1681-90.

34 Laine L, Harper S, Simon T, Bath R, Johanson J, Schwartz H, et al. A randomized trial comparing the effect of rofecoxib, a cyclooxygenase 2specific inhibitor, with that of ibuprofen on the gastroduodenal mucosa of patients with osteoarthritis. Gastroenterology 1999;117:776-83.

35 Bombardier C, Laine L, Reicin A, Shapiro D, Burgos-Vargas R, Davis B, et al. Comparison of upper gastrointestinal toxicity of rofecoxib and naproxen in patients with rheumatoid arthritis. VIGOR study group. N Engl J Med 2000;343:1520-8.

36 Silverstein FE, Faich G, Goldstein JL, Simon LS, Pincus T, Whelton A, et al. Gastrointestinal toxicity with celecoxib vs nonsteroidal anti-inflammatory drugs for osteoarthritis and rheumatoid arthritis. The CLASS study: a randomized controlled trial. JAMA 2000;284:1247-55.

37 Juni P, Rutjes AWS, Dieppe PA. Are selective COX 2 inhibitors superior to traditional non-steroidal anti-inflammatory drugs? BMJ 2002;324:1287-8.

38 Deeks JJ, Smith LA, Bradley MD. Efficacy, tolerability, and upper gastrointestinal safety of celecoxib for treatment of osteoarthritis and rheumatoid arthritis: a systematic review of randomised controlled trials. BMJ 2002;325:619-26

39 Rordorf C, Kellett N, Mair S, Ford M, Milosavljev S, Branson J, et al. Gastroduodenal tolerability of lumiracoxib versus placebo and naproxen: a pilot endoscopic study in healthy male subjects. Aliment Pharmacol Ther 2003; 18:533-41 